\title{
RECENT UPGRADES OF THE EOLE AND AIAS LIDAR SYSTEMS OF THE NATIONAL TECHNICAL UNIVERSITY OF ATHENS OPERATING SINCE 2000 IN ATHENS, GREECE
}

\author{
A. Papayannis', ${ }^{1}$ P. Kokkalis ${ }^{2}$, M. Mylonaki ${ }^{1}$, R. Soupiona ${ }^{1}$, C. A. Papanikolaou ${ }^{1}$, R. Foskinis ${ }^{1}$, \\ and A. Giakoumaki ${ }^{1}$ \\ ${ }^{I}$ National Technical University of Athens, Laser Remote Sensing Laboratory, Physics Department, \\ 15780 Zografou, Greece \\ ${ }^{2}$ Kuwait University, Faculty of Science, Kuwait \\ *Email: apdlidar@central.ntua.gr
}

\begin{abstract}
The technical specifications and advances/ upgrades of the stationary (EOLE) and mobile (AIAS) lidars located at the National Technical University of Athens (NTUA) are presented in this paper. EOLE is a multi-wavelength combined backscatter/Raman lidar system, which is part of the EARLINET lidar network since May 2000. AIAS is a mobile $532 \mathrm{~nm}$ elastic depolarization lidar system. Both instruments have been upgraded during 2019, in the frame of PANACEA to be part of the Greek National Research Infrastructure for aerosol research, under the umbrella of the European Strategy Forum on Research Infrastructures (ESFRI).
\end{abstract}

\section{INTRODUCTION}

Since 2000, the Laser Remote Sensing Unit (LRSU) of NTUA [37.96 $\mathrm{N}, 23.78^{\circ} \mathrm{E}, 212 \mathrm{~m}$ asl.] is operating the EOLE lidar system. Through these years, the system has been gradually upgraded regarding its operational wavelengths and configuration. Nowadays, EOLE is an advanced 6-wavelength elastic-Raman lidar system (Fig. 1), equipped with two depolarization channels (355 and $532 \mathrm{~nm}$ ), able to perform independent and simultaneous measurements of the vertical profiles of the aerosol backscatter coefficient at 354.93, 532 and $1064.2 \mathrm{~nm}$, aerosol extinction coefficient and linear particle depolarization ratio at 354.93 and $532 \mathrm{~nm}$, water vapor mixing ratio (using the $\mathrm{H}_{2} \mathrm{O}$ Raman channel at $407 \mathrm{~nm}$ ) and ozone in the troposphere [1-3]. Here we will limit our presentation on the aerosol measurement profiling.

\section{EXPERIMENTAL SET-UP}

The advanced elastic-Raman lidar system (EOLE) of LRSU is based on a pulsed Nd:YAG laser system (Spectra Physics Lab-170-10) (Fig. 1) which emits, simultaneously, pulses at 354.93532-1064.2 nm, with energies of 240-310-260 mJ, respectively, at $10 \mathrm{~Hz}$ repetition frequency. The laser beams are horizontally polarized $(>90 \%)$ at $532-1064.2 \mathrm{~nm}$ and vertically polarized $(>90 \%)$ at $354.93 \mathrm{~nm}$. The laser beam containing all three wavelengths is expanded by an achromatic Galilean telescope (x3), before being emitted in the atmosphere, thus its divergence remains $<0.17$ $\operatorname{mrad}$ (FWHM). A $300 \mathrm{~mm}$ diameter Cassegrainian telescope (focal length $\mathrm{f}=600 \mathrm{~mm}$, $\mathrm{FOV}=1.5 \mathrm{mrad})$ collects all elastically backscattered lidar signals (354.93-532-1064.2 $\mathrm{nm})$, as well as those generated by the spontaneous Raman effect (by atmospheric $\mathrm{N}_{2}$ at 386.6-607.4 $\mathrm{nm}$ and by $\mathrm{H}_{2} \mathrm{O}$ at $407.5 \mathrm{~nm}$ ).

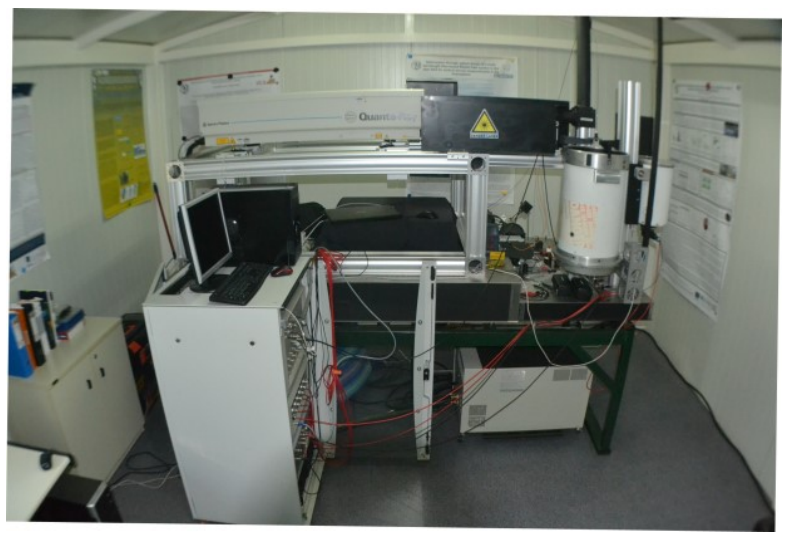

Figure 1. The LRSU elastic-Raman lidar (EOLE).

A second laser is used to emit vertically polarized beam at $355 \mathrm{~nm}(>99 \%)$, while an additional telescope $(200 \mathrm{~mm}$ diameter, Dall-Kirkham Cassegrainian) with focal length $\mathrm{f}=1000 \mathrm{~mm}$, collects the elastically backscattered lidar signals at 355 and $532 \mathrm{~nm}$ (at 2 polarization planes: 
parallel and vertical), which are optically separated by polarizing beam splitter cubes.

At the entrance of the $300 \mathrm{~mm}$ diameter telescope a high grade fused silica optical fiber (N.A. $=0.22 \pm 0.02$ and $1.5 \mathrm{~mm}$ core diameter) is used to transfer the lidar signals to the 6-wavelength spectrometer, which is equipped with achromatic collimating lenses, dichroic beam splitters, as well as doublets, eye pieces and interference filters (IFF) placed in front of the detectors (Photomultiplier tubes-PMTs at 354.93-386.6-407.5-532$607.4 \mathrm{~nm}$ and Avalanche Photo Diode at 1064.2 $\mathrm{nm})$. In Table 1 the technical characteristics of the receiving system of EOLE are summarized.

\begin{tabular}{|c|c|c|c|c|c|c|}
\hline & $\begin{array}{c}\mathbf{3 5 4 . 9} \\
\mathbf{n m}\end{array}$ & $\begin{array}{c}\mathbf{3 8 6 .} \\
\mathbf{6} \\
\mathbf{n m}\end{array}$ & $\begin{array}{c}\mathbf{4 0 7 .} \\
\mathbf{5} \\
\mathbf{n m}\end{array}$ & $\begin{array}{c}\mathbf{5 3 2} \\
\mathbf{n m}\end{array}$ & $\begin{array}{c}\mathbf{6 0 7 . 4} \\
\mathbf{n m}\end{array}$ & $\begin{array}{c}\mathbf{1 0 6 4 . 2} \\
\mathbf{n m}\end{array}$ \\
\hline $\begin{array}{c}\text { IFF } \\
\text { bandwidth } \\
\text { (nm, } \\
\text { FWHM) }\end{array}$ & 1.8 & 0.84 & 0.5 & 0.5 & 1.06 & 0.97 \\
\hline $\begin{array}{c}\text { Transmissi } \\
\text { on (\%) }\end{array}$ & 47.5 & 77.4 & 51 & 45 & 78.7 & 45.7 \\
\hline $\begin{array}{c}\text { Out of } \\
\text { band } \\
\text { blocking } \\
\text { (>OD) }\end{array}$ & 6 & 8 & 10 & 4 & 6 & 4 \\
\hline $\begin{array}{c}\text { Detector } \\
\text { model- } \\
\text { Hamamats } \\
\mathrm{u}\end{array}$ & $\begin{array}{c}\text { R7400 } \\
\text { P-03 }\end{array}$ & $\begin{array}{c}\text { R74 } \\
\text { P06 }\end{array}$ & $\begin{array}{c}\text { R74 } \\
00 \mathrm{U}-\end{array}$ & $\begin{array}{c}\text { R74 } \\
00- \\
\text { P02 }\end{array}$ & $\begin{array}{c}\text { R7400 } \\
\text { U-20 }\end{array}$ & $\begin{array}{c}\text { APD- } \\
1.5\end{array}$ \\
\hline \begin{tabular}{c} 
Eye-piece \\
\hline
\end{tabular} & YES & YES & YES & YES & YES & YES \\
\hline
\end{tabular}

Table 1. Technical characteristics of the optical components of the wavelength separation system of EOLE.

All optical components of the 6-wavelength spectrometer are mounted on micrometric positioners and rotators, fixed on an anti-vibrating optical table; therefore, they can be placed at an optimal position. The choice of the optical components, as well as their optimal position has been identified through advanced ray-tracing code (Zemax), by simulating the projection of the laser beam down to the PMTs' photocathodes. Narrowband IFFs are used to suppress the atmospheric background noise at the detected wavelengths (354.93-354.93-386.6-407.5-532607.4-1064.2 nm) (cf. Table 1).
The PMTs (operating both in the analog and photon-counting mode) and APD (operating in the analog mode) output signals, are fed into fast transient recorders (Licel $\mathrm{GmbH})$ working in both the analog (using $20 \mathrm{MHz}$ Analog to Digital Converters-ADC at 12-bits resolution) and photon counting (maximum $250 \mathrm{MHz}$ count rates) mode, at 8196 range bins. EOLE's overlap distance is of $\sim 600 \mathrm{~m}$, while the vertical raw resolution of the acquired lidar signals is $7.5 \mathrm{~m}$.

\subsubsection{Mobile two-wavelength depolarization elastic lidar system}

Additionally, a Raymetrics S.A. (Greece) vanmounted $1064 \mathrm{~nm}$ (elastic) and $532 \mathrm{~nm}$ (elastic) depolarization lidar (AIAS) is available (Fig. 2), to provide the vertical aerosol linear depolarization ratio in the troposphere, thus evaluating the sphericity of the probed aerosols. AIAS is based on a pulsed Nd:YAG laser system (Litron Nano SG 150-10 Series) which emits pulses at 532 and $1064.2 \mathrm{~nm}$, with energies of 95 and $55 \mathrm{~mJ}$, respectively, at $10 \mathrm{~Hz}$ repetition frequency.

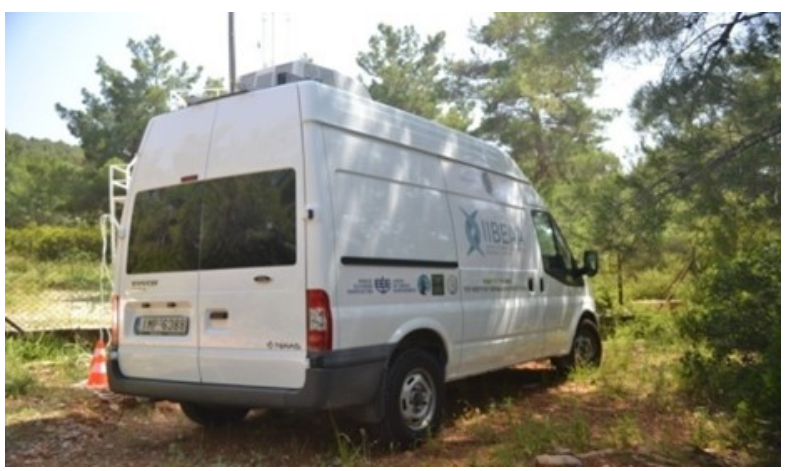

Figure 2. The $532 \mathrm{~nm}$ LRSU elastic depolarization lidar (AIAS lidar).

The laser beam at $532 \mathrm{~nm}$ is vertically polarized ( $>99 \%$ ) using a $\lambda-2$ waveplate and is expanded by a Galilean telescope $(x 4)$, before being emitted in the atmosphere, thus its divergence remains $<0.4$ mrad.

A $200 \mathrm{~mm}$ diameter Dall-Kirkham Cassegrainian telescope (focal length $\mathrm{f}=1000 \mathrm{~mm}$ ) collects the elastically backscattered lidar signals at $532 \mathrm{~nm}$ (at 2 polarization planes: parallel and vertical) and at $1064 \mathrm{~nm}$. A secondary mirror is used to guide the backscattered light to wavelength separation unit (WSU), which is equipped with collimating lenses, dichroic beam splitters, polarizing cubes, as well as doublets and very narrow $(0.6 \mathrm{~nm}$ 
FWHM) interference filters (IFF) placed in front of the detectors (Photo-multiplier tubes-PMTs at $532 \mathrm{~nm}$ ). A dichroic mirror is used to separate the $532 \mathrm{~nm}$ from the $1064.2 \mathrm{~nm}$ signals, while a polarizing cube beam splitter mounted in a rotating base, is used to separate the co-polarized and de-polarized light at $532 \mathrm{~nm}$, and to calibrate the signals.

\begin{tabular}{|c|c|c|}
\hline & $\begin{array}{c}\mathbf{5 3 2} \mathbf{~ n m} \\
\text { (p and s- } \\
\text { polarization) }\end{array}$ & $\begin{array}{c}\mathbf{1 0 6 4} \\
\mathbf{n m}\end{array}$ \\
\hline $\begin{array}{c}\text { IFF bandwidth (nm, } \\
\text { FWHM) }\end{array}$ & 0.6 & 0.97 \\
\hline $\begin{array}{c}\text { Transmission (\%) } \\
\text { Out of band blocking } \\
\text { (>OD) }\end{array}$ & 44.24 & 45.70 \\
\hline $\begin{array}{c}\text { Detector model- } \\
\text { Hamamatsu }\end{array}$ & R7400U-P02 & $\begin{array}{c}\text { Si-APD- } \\
3.0\end{array}$ \\
\hline Eye-piece & YES & YES \\
\hline
\end{tabular}

Table 2. Technical characteristics of the optical components of the wavelength separation system of AIAS.

Both EOLE [2] and AIAS [3] lidars follow the quality assurance protocols of EARLINET and have been validated through direct intercomparisons, both at hardware and software level, in the frame of the EARLINET, ASOS and ACTRIS projects [4-7].

\section{The PANACEA PROJECT}

The PANhellenic infrastructure for Atmospheric Composition and climatE change (PANACEA) is a Research Infrastructure (RI) where specialized atmospheric observations (aiming to adequately monitor the atmospheric composition, radiation disturbances and essential climate variables) will be performed. Thus, PANACEA is envisioned to be a distributed European RI (adopting the ACTRIS/ESFRI structure according to the EU Regulation 651/26.6.2014) to provide specific services to stakeholders, as well as a network of excellence at national level.

The specific objectives of PANACEA are to:
- create a novel RI of excellence in atmospheric sciences that will catalyze collaboration at national and international level, minimizing costs and enhancing networking and mobility through intra- and trans-national access;

- promote development of new technologies for atmospheric observation of aerosols, clouds, radiation, greenhouse and trace gases, in close partnership with national and European Union SMEs;

- provide access to tools and data, allowing various beneficiaries (e.g. scientific community, institutions, Regions, local/national authorities, large companies/industries and SMEs, NGOs) to exploit and develop synergistic atmospheric characterization techniques;

- improve the efficiency of current facilities, through the application of tailored harmonization processes; promote $\mathrm{QA} / \mathrm{QC}$ via creation of specialized calibration centers;

- provide access to high-quality information and services to end-users (research community, education, local/regional/national authorities, large companies/industries/SMEs, environmental and health protection agencies, energy, tourism and transport sectors, international organizations and networks, NGOs, etc.);

- provide state-of-the-science expertise, assisting policy making on issues such as climate change, natural hazards, air quality and long-range transport of pollutants;

- create and use educational and training platforms for students and young scientists in the fields of air quality and climate change.

\section{ACKNOWLEDGMENTS}

The LRSU-NTUA elastic-Raman system is member of the EARLINET network (www.earlinet.org). We acknowledge support of this work by the project "PANhellenic infrastructure for Atmospheric Composition and climatE change" (MIS 5021516) which is implemented under the Action "Reinforcement of the Research and Innovation Infrastructure", funded by the Operational Programme "Competitiveness, Entrepreneurship and Innovation" (NSRF 2014-2020) and co-financed 
by Greece and the European Union (European Regional Development Fund) (https://panaceari.gr). The Biomedical Research Foundation of the Academy of Athens (BRFAA) is acknowledged for the provision of its mobile platform to host the NTUA AIAS lidar system.

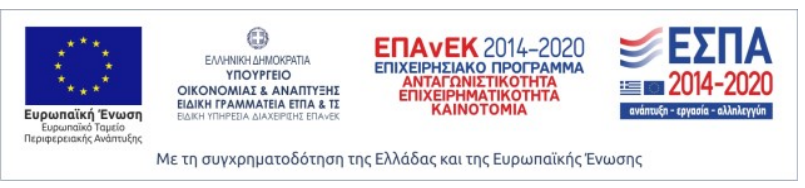

\section{REFERENCES}

[1] Mamouri, R.E., A. Papayannis, G. Tsaknakis, et al., First water vapor measurements over Athens, Greece, obtained by a combined Raman-elastic backscatter lidar system, Optica Pura Y Applicada 41, 109-116 (2008).

[2] Kokkalis, P., A. Papayannis, R. E. Mamouri, et al., The EOLE lidar system of the National Technical University of Athens, 629-632, $26^{\text {th }}$ International Laser Radar Conference (26 $6^{\text {th }}$ ILRC), 25-29 June 2012, Porto Heli, Greece.

[3] Papayannis, A., D. Balis, P. Kokkalis, R. Mamouri, G. Tsaknakis, E. Giannakaki, N. Siomos, V. Amiridis, ARIADNE: The Greek Lidar Network, 349-352, $26^{\text {th }}$ International Laser Radar Conference (26 $6^{\text {th }}$ ILRC), 2529 June 2012, Porto Heli, Greece.

[4] Freudenthaler, V., The telecover test: A quality assurance tool for the optical part of a lidar system, Proc. $24^{\text {th }}$ International Laser Radar Conference, 145146 (2008).

[5] Pappalardo, G., A. Amodeo, U. Wandinger, et al., Aerosol lidar intercomparison in the frame of EARLINET: Part III: Aerosol extinction Raman lidar algorithm intercomparison, Applied Optics 43, 53705385 (2004).

[6] Amodeo, A., et al., Proc. $28^{\text {th }}$ International Laser Radar Conference, EPJ Web of Conferences 176, 09008 (2018).

[7] Müller, D., U. Wandinger, and A. Ansman, Microphysical particle parameters from extinction and backscatter lidar data by inversion with regularization: theory, Applied Optics 38, 2346-2357 (1999). 